\title{
Manifestation of an adaptive neuro-fuzzy model on landslide susceptibility mapping: Klang valley, Malaysia
}

\begin{abstract}
The purpose of the present paper is to manifest the results of the neuro-fuzzy model using remote sensing data and GIS for landslide susceptibility analysis in a part of the Klang Valley areas i Malaysia. Landslide locations in the study area were identified by interpreting aerial photographs and satellite images, supported by extensive field surveys. SPOT 5 satellite imagery was used to map vegetation index. Maps of topography, lineaments, NDVI and land cover were constructed from the spatial datasets. Seven landslide conditioning factors such as altitude, slope angle, plan curvature, distance from drainage, soil type, distance from faults and NDVI were extracted from the spatial database. These factors were analyzed using a neuro-fuzzy model (adaptive neuro-fuzzy inference system, ANFIS) to construct the landslide susceptibility maps. During the model development works, total 5 landslide susceptibility models were obtained by using ANFIS results. For verification, the results of the analyses were then compared with the field-verified landslide locations. Additionally, the ROC curves for all landslide susceptibility models were drawn and the area under curve values was calculated. Landslide locations were used to validate results of the landslide susceptibility map and the verification results showed $98 \%$ accuracy for the model 5 employing all parameters produced in the present study as the landslide conditioning factors. The validation results showed sufficient agreement between the obtained susceptibility map and the existing data on landslide areas. Qualitatively, the model yields reasonable results which can be used for preliminary landuse planning purposes. As a conclusion, the ANFIS is a very useful tool for regional landslide susceptibility assessments.
\end{abstract}

Keyword: ANFIS model; Landslide susceptibility; GIS; Malaysia; Remote sensing; Klang valley; Malaysia 